\title{
RELACIONAMENTOS INTERORGANIZACIONAIS ENTRE EMPRESAS EXPORTADORAS E ASSESSORIAS EM COMÉRCIO EXTERIOR: UM ESTUDO EM DÍADES NO SETOR MOVELEIRO*
}

Data de submissão: 31/05/2014 Aceite: 29/06/2016

\author{
Tatiane Pellin Cislaghi ${ }^{1}$ \\ Fabiano Larentis ${ }^{2}$ \\ Vilmar Antonio Gonçalves Tondolo \\ Gabriel Sperandio Milan ${ }^{4}$
}

\section{RESUMO}

Este estudo objetivou analisar os relacionamentos interorganizacionais (RIOs) entre empresas focais (indústrias moveleiras exportadoras) e membros de apoio (assessorias em comércio exterior), no contexto de cadeias de suprimento no setor moveleiro. Efetuou-se um estudo de casos múltiplos em três díades. Os resultados indicaram que, com o desenvolvimento dos RIs, a confiança adquirida permitiu qualificar a prestação de serviços. Identificou-se, ainda, que o contato pessoal mais frequente - os funcionários das díades investigadas se conhecerem pessoalmente - permitiu um melhor RIO. Por outro lado, o distanciamento das relações causou o afastamento entre setores envolvidos e insatisfações diante da carência das assessorias em apresentar inovações.

Palavras-chave: Relacionamentos interorganizacionais; Cadeias de suprimento; Setor moveleiro; Relacionamentos diádicos.

\footnotetext{
* Agradecimentos: Professora do Instituto Federal de Educação, Ciência e Tecnologia do Rio Grande do Sul - IFRS, contemplada com fomento através de afastamento.

1 Possui graduação em Administração com Habilitação em Comércio Exterior pela Universidade de Caxias do Sul, UCS, mestrado em Administração pela Universidade de Caxias do Sul, UCS e doutoranda em Administração pela Universidade do Vale do Rio dos Sinos, UNISINOS. Professora do Instituto Federal de Educação, Ciência e Tecnologia do Rio Grande do Sul - IFRS Campus Bento Gonçalves. E-mail: tatiane.cislaghi@bento.ifrs.edu.br

2 Possui graduação em Administração pela Universidade de Caxias do Sul, UCS, mestrado em Administração pela Universidade Federal do Rio Grande do Sul, UFRGS e é doutor em Administração pela Universidade Federal do Rio Grande do Sul, UFRGS. Professor da Universidade de Caxias do Sul, UCS. E-mail: flarenti@ucs.br

3 Possui graduado em Administração de Empresas pela Universidade Federal do Rio Grande, FURG, mestrado em Administração de Empresas pela Universidade do Vale do Rio dos Sinos, UNISINOS, doutorado em Administração pela Universidade do Vale do Rio dos Sinos, UNISINOS. Professor da Universidade Federal de Pelotas, UFPEL. E-mail: vtondolo@gmail.com

4 Possui graduação em Administração de Empresas pela Universidade de Caxias do Sul, UCS, mestrado em Engenharia de Produção pela Universidade Federal do Rio Grande do Sul, UFRGS e doutorado em Engenharia de Produção pela Universidade Federal do Rio Grande do Sul, UFRGS. Professor da Universidade de Caxias do Sul, UCS. E-mail: gsmilan@ucs.br
} 


\section{INTRODUÇÃO}

Relacionamentos interorganizacionais (RIOs) ocorrem e se formam por diversas razões, bem como as dimensões que os constituem (RIBEIRO; SILVA; PRADO, 2009). Para se desenvolverem, não necessitam apenas de investimentos de recursos e da seleção dos melhores parceiros, mas também de dimensões tais como confiança, satisfação, lealdade, comprometimento, troca de informações, cooperação, poder, entre outras (GUMMESSON; 2005, PALMATIER et al., 2006).

Além disso, redes, cadeias de suprimentos e relacionamentos interorganizacionais são alguns tipos de vínculos complexos de negócios que vão desde uma rede de conexões a uma relação diádica (BAKER, 1990; CLARO, 2004). Pereira e Bellini (2006) argumentam que a unidade de análise de uma relação diádica é o relacionamento entre duas partes e, devido à interdependência mútua entre elas, a pesquisa da díade de maneira consistente precisa refletir padrões, relações ou interações entre os parceiros.

Conforme mencionado por Maloni e Benton (1997), é a construção dos Rls que minimiza as barreiras entre os agentes que compõem a díade. A motivação para o relacionamento, segundo Pirani e Cunha (2010), considera a socialização dos atores, que tendem a interagir com outros que possuam semelhanças nas atitudes, recursos, competências e comportamentos. Nesse sentido, as organizações, ao possibilitarem a combinação de seus recursos por meio da articulação de relações, podem obter vantagens competitivas sobre seus concorrentes, que muitas vezes sozinhas não obteriam (DYER; SINGH, 1998).

Merece menção também o aumento da orientação relacional e da prestação de serviços, a qual resulta em aumento dos níveis de ação conjunta e de cooperação, maior confiança e uma troca de informações mais vantajosa na díade (GULATI; SYTCH, 2007). Essa comunicação entre os parceiros acaba por reduzir o índice de erros nos processos, além de melhorar a qualidade da relação e o tempo de resposta ao cliente (DYER, 1996; CHEN; PAULRAJ, 2004). Os membros de apoio contratados representam a empresa focal frente ao seu cliente final, portanto o desempenho deste reflete-se automaticamente na contratante.

Objetiva-se, dessa forma, analisar os RIOs no contexto da cadeia de suprimentos, especificamente entre empresas focais e membros de apoio. De forma específica, (i) caracterizar os processos envolvidos nos RIOs; (ii) analisar dimensões constituintes dos Rls selecionados (troca de informações, confiança, comprometimento, cooperação, satisfação, lealdade e poder); e (iii) identificar barreiras encontradas nos RIOs. O campo de estudo é constituído por três assessorias em comércio exterior (membros de apoio) e três empresas exportadoras do setor moveleiro (empresas focais), ou seja, três díades.

O estudo justifica-se pois a maior parte da literatura de cadeias de suprimento, segundo Chen e Paulraj (2004), é muitas vezes limitada a aspectos financeiros, ou considera apenas uma empresa focal (comprador/fornecedor), não se estendendo a díades. Ademais, Alighieri e Filho Zanquetto (2009) afirmam que são poucos os estudos que salientam os RIOs em prestadoras de serviços, nas quais não existe o fluxo de produtos, mas sim de informações. Verifica-se que há uma tendência de crescimento das publicações na área de serviços, sendo temas oportunos gestão de redes de suprimentos globais e redes de suprimento e suas inter-relações (BORTOLLOSSI; SAMPAIO, 2012).

Para tanto, o documento está organizado em cinco seções. Além desta introdução, a fundamentação teórica compõe a segunda seção. Em seguida, encontram-se os aspectos metodológicos. A quarta seção diz respeito à análise de dados e discussão dos resultados, seguindo com as considerações finais. 


\section{REFERENCIAL TEÓRICO}

\subsection{Relacionamentos Interorganizacionais}

As relações entre as empresas evoluem ao longo do tempo e são fundamentalmente dinâmicas, ou seja, os componentes desses relacionamentos apresentam um papel importante no desempenho dos membros envolvidos (PALMATIER et al., 2013).

Considerando-se os RIOs, pelo menos duas organizações interagem em determinado contexto, ou seja, estabelecem uma díade (LARENTIS; ANTONELLO; SLONGO, 2010). Os RIOs possuem algumas funções básicas descritas por Håkansson e Snehota (1995), entre elas, ter a função de unir duas organizações (função de díade), a qual significa ser desenvolvido por duas empresas estabelecidas e em conexão em suas atividades, recursos e camadas de agentes. A díade possui ainda, como objetivo, não somente somar duas partes, mas iniciar algo qualitativamente distinto.

Ademais, a duração do relacionamento pode influenciar positivamente o comportamento colaborativo das empresas. Portanto, em relacionamentos mais antigos, as ações conjuntas tendem a um maior êxito (ANDERSON; WEITZ, 1989; CLARO; CLARO, 2004). Em complemento, Grandori e Soda (1995) afirmam que os Rls são importantes tanto economicamente, por regular a interdependência entre transações muitas vezes complexas, como em relação à interdependência cooperativa entre as empresas. Destaca-se que a definição adotada para o estudo para relacionamentos interorganizacionais (RIOs) é de Oliver (1990), o qual os conceitua como transações relativamente contínuas, com fluxos e ligações que ocorrem entre uma organização e outra, ou mais organizações em seu ambiente.

No contexto de serviços, Gummesson (2005) considera crucial para um adequado RIO a habilidade do prestador de serviços em projetar e entregar o serviço. Além disso, Grönroos (2003) complementa que é importante distinguir três importantes requisitos estratégicos de um relacionamento: (i) redefinir o negócio como um negócio de serviço, tendo como elemento-chave a concorrência por serviço; (ii) compreender a organização na perspectiva de gerenciamento de processo e não de uma perspectiva de funções; e (iii) desenvolver uma rede de parcerias, a fim de cuidar o processo de serviço como um todo.

\subsubsection{Relacionamentos Interorganizacionais no contexto das cadeias de suprimentos}

A Gestão da Cadeia de Suprimentos (GCS), de acordo com Lambert e Cooper (2000), apresenta-se como uma nova maneira de administrar negócios e seus relacionamentos, lidando com a excelência nos processos de negócios. Mentzer et al. (2001) descrevem que a GCS é definida como coordenação sistemática e estratégica de funções empresariais tradicionais e táticas, usadas na relação entre essas funções dentro de uma organização e através de negócios dentro da mesma cadeia de suprimentos, com o propósito de melhorar o desempenho a longo prazo de empresas individualmente e da cadeia como um todo.

Destaca-se que a GCS é composta por membros primários e de suporte ou apoio. Os primários são as empresas ou unidades de negócio que executam atividades (operacionais ou gerenciais) que agregam valor ao longo da cadeia de suprimentos de determinado produto ou serviço. Já os membros de apoio fornecem recursos, troca de informações, entre outros serviços, suportando os membros primários da cadeia, porém não participando de forma direta no processo de agregação de valor (LAMBERT; COOPER, 2000). Agregar valor, de acordo com os autores, é diferenciar-se conhecendo o cliente, seus hábitos, preferências e valores. Destaca-se que a agregação de valor entre os membros da cadeia de suprimentos pode revelar se os elos estão propor- 
cionando o valor esperado pelos clientes finais e demonstrar se as competências dos membros estão sincronizadas e são complementares, para maximizar o nível de serviço esperado. Ainda, agregar valor a um produto ou a um serviço representa a interação com o cliente, a qual depende da satisfação e lealdade, não só dos clientes, mas de toda a cadeia (VARGO; LUSCH, 2006).

Além disso, as atividades da cadeia de valor das organizações podem ser compartilhadas, possibilitando ganhos competitivos (Porter, 1999). Em geral, essa integração permite ganhos como a agregação de valor ao produto, acesso ao mercado e capacitação tecnológica (SIMCHI-LEVI; KAMINSKY; SIMCHI-LEVI, 2003).

Por outro lado, o relacionamento entre comprador/fornecedor pode ser considerado como o conjunto de estratégias interorganizacionais empregadas pelas empresas compradoras e fornecedoras em suas negociações (CUNHA; ZWICKER, 2009). Verifica-se, ainda, que os relacionamentos entre clientes e fornecedores se referem a todas as atividades ligadas ao estabelecimento, desenvolvimento e manutenção de trocas relacionais (LADEIRA; MARCONATTO; ESTIVALETE, 2012). Trocas relacionais, de acordo com Sirdeshmukh, Singh e Sabol (2002), compreendem estudar as relações, a fim de constituir relacionamentos fortes e de longo prazo. Quase sempre nas trocas relacionais há uma assimetria de poder. Um dos pontos-chave para minorar esse efeito assimétrico em trocas relacionais de serviços é obter a confiança do consumidor. Como complemento, trocas relacionais são aquelas que ocorrem entre as partes que constituem relacionamentos interorganizacionais fortes e de longo prazo - baseadas em atributos como confiança e compromisso (MORGAN; HUNT, 1994).

Diferente das trocas transacionais ou discretas, onde não há preocupação das partes em se engajarem a longo prazo, nas trocas relacionais há a preocupação das empresas em manter relacionamentos de longo prazo, altos níveis de cooperação, planejamento conjunto, adaptação e atendimento das necessidades de maneira que sejam mutuamente benéficos aos partícipes (LAMBE; SPEAKMAN; HUNT, 2000). A troca relacional é motivada pelo reconhecimento mútuo de que os resultados desse tipo de troca excedem o nível que poderia ser adquirido a partir de outras formas de troca ou permuta com um parceiro diferente (DWYER; SHURR; OH, 1987; LAMBE; SPEAKMAN; HUNT, 2000).

A integração das atividades pela cadeia de suprimentos exige relacionamentos próximos de trabalho, o que envolve o compartilhamento de informações por diferentes empresas e o uso de equipes de pessoas que ultrapassam os limites organizacionais, colaborando entre si. Uma GCS efetiva envolve a gestão de trocas relacionais com outros membros da cadeia (TAYLOR, 2005; ESPER; DEFEE; MENTZER, 2010; HUTT; SPEH, 2011). Nesse sentido, considerando a importância dos RIOs para a GCS, Esper, Defee e Mentzer (2010) apresentam a Orientação para a Cadeia de Suprimentos (OCS), a qual se considera a visão holística da cadeia de suprimentos competir através das competências desenvolvidas na cadeia e enfatizar o trabalho e relacionamento entre empresas. A OCS envolve: (i) desenho organizacional; (ii) gestão de pessoas; (iii) tecnologia da informação; e (iv) mensuração organizacional. Nesse ínterim, conforme identificado por Li (2011), fornecedores que estabelecem excelência em operações de serviços e se comprometem com relacionamentos próximos e fortes apresentam maiores níveis de satisfação e lealdade. Ainda, conforme Gomes et al. (2012), para se estabelecer um relacionamento eficaz e de longo prazo, além de o cliente estar satisfeito com o serviço prestado, também é preciso conhecer as suas necessidades, a fim de encurtar os laços de relacionamento e, com isso, fidelizá-lo. 


\subsection{Dimensões constituintes de RIs selecionadas para o estudo}

Esta subsecção apresenta as sete dimensões selecionadas a priori para o estudo. Oliver (1990) reforça que os determinantes das relações interorganizacionais se justificam principalmente por duas razões: (i) as organizações tomam decisões intencionais ao empreender relacionamentos interorganizacionais, em geral para transpor restrições que limitam ou influenciam as suas escolhas; e (ii) as dimensões explicam a razão de as empresas decidirem entrar em relacionamentos interorganizacionais.

Inicialmente, tomou-se como referencial o estudo de Agariya e Singh (2011), uma revisão de definições e construtos gerais dos relacionamentos, com base na teoria de marketing de relacionamento. $O$ artigo apresenta 72 definições propostas de 1982 a 2010, resultando em 50 principais definições com, no mínimo, dez citações. Os dez primeiros construtos foram: (1) confiança (167 citações); (2) satisfação/experiência (163 citações); (3) lealdade (84 citações); (4) comprometimento (71 citações); (5) qualidade do serviço (66 citações); (6) comunicação (57 citações); (7) empatia/orientação para o consumidor (38 citações); (8) qualidade, valor e duração do relacionamento (33 citações); (9) reciprocidade (29 citações); e (10) cultura (29 citações).

$\mathrm{Na}$ presente pesquisa, foram utilizadas as dimensões apresentadas por Agariya e Singh (2011) de acordo com o número de citações. Contudo, excluiram-se a quinta, a sétima, a oitava, a nona e a décima dimensão e incluiu-se a dimensão cooperação (que aparece em $48^{a}$ ), com base na análise de Palmatier et al. (2006). Substitui-se ainda a sexta dimensão pela 31a na pesquisa (comunicação por troca de informações), por esta apresentar-se como menos ampla.

Para a escolha da dimensão poder, fez-se uso do estudo proposto por Pigatto (2005), no qual pesquisou aspectos importantes em um relacionamento colaborativo. $O$ autor desenvolveu sua pesquisa a partir de onze dimensões: poder, dependência, investimento específico, comunicação, satisfação, adaptação, cooperação, comprometimento, confiança, conflito, e cultura e estrutura organizacional.

No Quadro 1, pode-se observar uma breve explanação de cada uma das dimensões selecionadas.

Quadro 1 - Dimensões selecionadas para o estudo

\begin{tabular}{|c|l|}
\hline Dimensão & \multicolumn{1}{c|}{ Aspectos principais } \\
\hline $\begin{array}{c}\text { Troca de infor- } \\
\text { mações }\end{array}$ & $\begin{array}{l}\text { Importante para a convergência de expectativas sobre parceiros e sobre obrigações não es- } \\
\text { pecificadas em contrato: parceiros em díades que utilizam a troca de informação de maneira } \\
\text { precisa e detalhada podem ganhar uma vantagem competitiva (GULATI; SYTCH, 2007); } \\
\text { Principal precursor de confiança é a comunicação (MORGAN; HUNT, 1994); confiança se ex- } \\
\text { pressa pela quantidade, frequência e qualidade das informações compartilhadas entre par- } \\
\text { ceiros (PALMATIER et al., 2006); } \\
\text { Determinante para o desempenho das empresas e um dos pré-requisitos mais importantes } \\
\text { para um RI bem-sucedido (DYER, 1996, 1997). }\end{array}$ \\
\hline Confiança & $\begin{array}{l}\text { Aceitação dos riscos associados aos tipos e intensidades das interdependências inerentes a } \\
\text { cada relacionamento. Pode ser contextualizada em quatro formas: (i) dependência superficial; } \\
\text { (ii) interdependência superficial; (iii) dependência intensa; e (iv) interdependência intensa, de- } \\
\text { terminando a natureza de interdependência entre as partes (SHEPPARD; SHERMAN, 1998); } \\
\text { Considerada um dos elementos-chave do relacionamento (MORGAN; HUNT, 1994); diz respeito } \\
\text { à confidencialidade das informações, bem como à sua veracidade (LARENTIS; SLONGO, 2008). }\end{array}$ \\
\hline $\begin{array}{c}\text { Comprometi- } \\
\text { mento }\end{array}$ & $\begin{array}{l}\text { Desejo permanente de manter um relacionamento baseado em valor entre os parceiros; } \\
\text { confiança é necessária para o comprometimento: ele existe quando uma das partes acre- } \\
\text { dita que o relacionamento é importante e desenvolve esforçOS para mantê-lo ou realçá-lo } \\
\text { (GRÖNROOS, 2003; MORGAN; HUNT, 1994); } \\
\text { Desejo contínuo de manter um relacionamento de valor, com afetividade, comportamen- } \\
\text { tos adequados, cumprimento de obrigações e normas: uma empresa ou pessoas sentem- } \\
\text { se motivadas a realizar negócios com outros participantes (PALMATIER et al., 2006). }\end{array}$ \\
\hline
\end{tabular}




\begin{tabular}{|c|c|}
\hline Cooperação & $\begin{array}{l}\text { Esforços conjuntos relacionados ao desempenho e planejamento sobre o tempo } \\
\text { (DWYER; SCHURR; OH, 1987); a cooperação é reforçada através da ação conjunta; im- } \\
\text { portante elemento de relações de troca bem-sucedidas (GULATI; SYTCH, 2007); } \\
\text { Ações coordenadas semelhantes ou complementares que refletem as expectativas } \\
\text { conjuntas das empresas envolvidas de alcançarem objetivos mútuos e individuais ao } \\
\text { longo do tempo (ANDERSON; NARUS, 1990); } \\
\text { É influenciada diretamente pelo comprometimento e pela confiança. Um parceiro } \\
\text { comprometido com o relacionamento vai cooperar em prol do bom funcionamento da } \\
\text { relação (MORGAN; HUNT, 1994). }\end{array}$ \\
\hline Satisfação & $\begin{array}{l}\text { Estado afetivo e emocional dos consumidores que tornam a relação tipicamente avaliada de } \\
\text { forma cumulativa ao longo da história de trocas (PALMATIER et al., 2006); comparação entre } \\
\text { o que era esperado e as percepções de desempenho, julgamento de um produto/serviço em } \\
\text { função do que proporcionou ou está proporcionando (OLIVER, 2010); } \\
\text { Aspecto importante para empresas, devido ao aumento das exigências dos consumidores e à } \\
\text { crescente oferta de produtos e/ou serviços (RADONS; TORRES; CERETTA, 2012); relação entre } \\
\text { qualidade e satisfação é positiva. } \\
\text { Pessoas tomam decisões pela satisfação que esperam obter ou punição que esperam evitar } \\
\text { (FORNELL, 2007). }\end{array}$ \\
\hline Lealdade & $\begin{array}{l}\text { Modelo multidimensional combinando intenções, atitudes e indicadores de desempe- } \\
\text { nho do vendedor (PALMATIER et al., 2006); um compromisso mantido em recomprar } \\
\text { um produto/serviço preferido no futuro, causando compras repetidas (OLIVER, 1999); } \\
\text { Resulta (i) do vínculo emocional, baseado no afeto, e se configura pela incidência de } \\
\text { uma atitude positiva em relação à marca, desenvolvida de experiências sucessivas e } \\
\text { acumuladas; (ii) da necessidade de o cliente estar em consonância com as normas vi- } \\
\text { gentes na sociedade; (iii) do desejo de manter a preferência e o investimento em uma } \\
\text { determinada marca, produto ou serviço; e (iv) da falta de alternativas (ELLIS, 2000); } \\
\text { Tem-se que o desenvolvimento da lealdade do consumidor tem como requisito básico } \\
\text { a satisfação, visto que clientes satisfeitos tendem a efetuar a compra ou adquirir o } \\
\text { serviço novamente (GRÖNROOS, 1996). }\end{array}$ \\
\hline Poder & $\begin{array}{l}\text { Capacidade de impor-se sobre outros. Quanto maior a interdependência, maior a im- } \\
\text { portância da aplicação justa de poder nas transações (DWYER; SCHURR; OH, 1987); im- } \\
\text { portante fator a fim de identificar o grau de poder e influência de cada parte (CROOM; } \\
\text { ROMANO; GIANNAKIS, 2000); habilidade do indivíduo ou de um grupo para influenciar } \\
\text { o comportamento dos outros: capacidade de fazer com que alguém faça o que não } \\
\text { teria feito de outro jeito (HUNT; NEVIN, 1974; GASKI, 1984); } \\
\text { Alguns tipos de poder: possuído e realizado. O poder realizado é o resultado do exer- } \\
\text { cício do possuído, a fim de provocar mudanças nos comportamentos do outro (HE; } \\
\text { GHOBADIAN; GALLEAR, 2013). Tem-se ainda o (i) poder formal, dividido em coercitivo, } \\
\text { poder de recompensa, legítimo e poder de informação, e o (ii) pessoal, dividido em } \\
\text { poder de talento, de referência e de carisma (ROBBINS, 2005). }\end{array}$ \\
\hline
\end{tabular}

\section{ASPECTOS METODOLÓGICOS}

Tendo em vista a problemática de pesquisa, os objetivos propostos e os temas pesquisados, como delineamento efetuou-se uma pesquisa qualitativa e exploratória-descritiva combinada (MARCONI; LAKATOS, 2002). A estratégia foi o estudo de caso múltiplo, especialmente por haver a necessidade de explorar processos e comportamentos dos quais se tem uma compreensão limitada a respeito (FLYVBJERG, 2006; GODOY, 2007; MERRIAN, 2009; YIN, 2010). Compreende, dessa forma, uma pesquisa qualitativa, a fim de permitir ao pesquisador o aprofundamento no tema; exploratória, pela busca por informações sobre o objeto de estudo, neste caso os relacionamentos interorganizacionais no contexto das cadeias de suprimento; por fim, descritiva, de forma a caracterizar o objeto de estudo, no sentido de apresentar os dados do ramo moveleiro (principalmente no estado do Rio Grande do Sul), bem como informações sobre as assessorias em comércio exterior.

A unidade de análise está representada pelo RIO em três díades (indústrias moveleiras e assessorias em comércio exterior), diferentes entre si. A unidade de análise díade é o relacionamento entre duas partes, devendo considerar padrões e interações entre os parceiros (PEREIRA; 
BELLINI, 2006). Optou-se por tais organizações moveleiras, já que elas possuem uma larga participação no setor, tanto em tempo (tradição no mercado) quanto em volume de produção, como mercados de atuação, principalmente internacionais, além do papel social e econômico para as cidades nas quais estão inseridas. Como complemento, a escolha das assessorias se deveu ao tempo e frequência dos relacionamentos com as empresas focais, uma vez que, segundo Dwyer, Schurr e Oh (1987), relacionamentos mais longos e frequentes entre organizações apresentam características interessantes ao estudo. Ambas atuam há diversos anos em seus segmentos (Assessorias E e G, desde 1996; Assessoria C, desde 1997) e possuem uma vasta experiência no comércio internacional. Salienta-se que o relacionamento interorganizacional na Díade $A$, composta pela Empresa B e Assessoria $E$, existe desde 2007. Já a Díade B, composta pela Empresa $M$ e Assessoria $\mathrm{G}$, teve início no ano de 2006. Por fim, a Díade C possui como membros a Empresa $T$ e Assessoria C, cuja relação data do ano de 2007.

O processo de coleta de dados utilizou a lógica da triangulação, que utiliza diferentes tipos e fontes de dados (YIN, 2010). Após definir a unidade de análise, a coleta ocorreu por meio de entrevistas pessoais em profundidade, análise documental e observações. Os respondentes foram os responsáveis pelos setores operacionais e gerentes do setor de exportação das indústrias do setor moveleiro e os funcionários que atendem diretamente tais empresas nas assessorias em comércio exterior, além dos seus gerentes comerciais.

A coleta foi realizada por meio de entrevista em profundidade (KING; HORROCKS, 2010) com cada informante-chave, de maio a julho de 2013, totalizando 16 entrevistas. No Apêndice A, encontra-se o roteiro completo. Aplicaram-se as mesmas questões para as indústrias moveleiras e para as assessorias em comércio exterior, alterando consequentemente o arquivo utilizado na pesquisa conforme o funcionário entrevistado. $\mathrm{Na}$ Díade $\mathrm{A}$, foram realizadas seis entrevistas (três na Empresa B e três na Assessoria E); na Díade B, o total foi de cinco entrevistas (duas na Empresa $M$ e três na Assessoria $G$ ); e na Díade $C$, foram também cinco as pessoas entrevistadas (duas na Empresa T e três na Assessoria C). Todas foram gravadas com os funcionários na sede de suas empresas, após agendamento, e posteriormente transcritas. A definição do número de entrevistados foi baseada no princípio da redundância (GODOI; MATTOS, 2006).

Por fim, para a análise de dados, utilizou-se a análise de conteúdo (BARDIN, 2000; PATTON, 1987; SCHREIER, 2012; SCOTT; GARNER, 2013). Como etapas de análise, adotaram-se as definidas por Flick (2009) como: (i) definição dos materiais e seleção das entrevistas; (ii) análise da situação da coleta de dados: evidenciar os participantes; (iii) caracterização formal do material: entrevistas gravadas e materiais salvos em arquivos eletrônicos; e (iv) direção da análise para os textos selecionados: Miles e Huberman (1994) descrevem como redução de dados, ou seja, um processo de seleção, focando e simplificando os dados obtidos.

No estudo, utilizaram-se protocolo de pesquisa (roteiro básico de questões e observações - conforme Apêndice A) e quadros desenvolvidos com as categorias de análise, ou seja, processos envolvidos nos RIs entre os membros de apoio e as respectivas empresas focais; dimensões dos Rls, subcategorias que foram definidas a priori (troca de informações, confiança, comprometimento, cooperação, satisfação, lealdade, poder); e barreiras encontradas nos RIOs. Após a transcrição de cada entrevista em um arquivo de texto único, elaboraram-se três quadros (um para cada díade estudada, com todos os funcionários entrevistados), com seis colunas cada: objetivos específicos, categorias de análise, resumo da entrevista, relato selecionado, questionamentos dos pesquisadores pós-entrevista e autores de base (relacionando citações do referencial teórico).

\section{ANÁLISE DOS DADOS E APRESENTAÇÃO DOS RESULTADOS}




\subsection{Caracterização dos processos envolvidos nos Rls das díades estudadas}

Para a caracterização dos processos envolvidos nos RIOs da Díade A (Empresa B e Assessoria E), Díade B (Empresa M e Assessoria G) e Díade C (Empresa T e Assessoria C), consideraram-se primeiramente a maneira como os contatos entre os membros são realizados, a frequência e a interação entre os partícipes e os atributos importantes para a escolha de um parceiro, seja como cliente, seja como prestador de serviços. Como síntese, tem-se que, apesar da relevância dos contatos por meio de e-mails, a fim de registrar os processos, a comunicação por telefone e de maneira pessoal, por meio de visitas, encontros, dentro ou fora do âmbito empresarial, facilitam o RIO, personalizando o serviço prestado e muitas vezes a qualidade e intensidade das relações. Destaca-se, nos processos envolvidos nas díades (elaboração e envio de documentos, trâmites logísticos e alfandegários necessários, entre outros), que as pessoas que mantêm contato no dia a dia dos setores operacionais, devido à frequência de troca de informações, tornam-se próximas na relação. Essa proximidade das pessoas e dos setores facilita ou dificulta os RIOs à medida que os serviços são desenvolvidos.

De forma geral, os papéis e orientações de ambas as empresas são bem definidos, e as assessorias são consideradas formadoras de profissionais para a área de comércio exterior da região. No que tange ao contato pessoal, principalmente por meio de visitas, ressalta-se a insatisfação nas Empresas B e T, que solicitam mais atenção de seus parceiros. Segundo Forti, Marson e Campello (2012), os prestadores de serviços estão perdendo clientes não somente por conta da concorrência, mas também, na maioria das vezes, por falhas no processo comercial. Os entrevistados indicaram que poderiam ser realizados encontros fora do horário de trabalho, como almoços ou jantares, oferta de outras atividades pelas empresas (palestras, treinamentos), até mesmo em feiras dos segmentos ou outros tipos de eventos afins.

Por outro lado, na Díade B, tal prática já é utilizada pelos membros. Segue relato da Analista da Assessoria G sobre o tema:

Começamos a perceber que o relacionamento muda. É muito fácil xingar quem tu não conhece; conhecer os clientes pessoalmente deixou o relacionamento profissional mais próximo. (Analista em Comércio Exterior - Assessoria G - Díade B).

Além disso, os entrevistados trazem o elemento da inovação como forma de diferenciação ao serviço oferecido, fato que não é recorrente em tais díades (Díade A e Díade C). Essa solicitação das indústrias reflete o que Gummesson (2005) considera crucial para um bom RIO, a habilidade do prestador de serviços em projetar e produzir o serviço, bem como seu sistema de produção e entrega, além da oferta de novas alternativas.

\subsection{Dimensões selecionadas dos RIs nas díades partícipes da pesquisa}

Na sequência, apresentam-se os resultados associados às dimensões dos RIs: troca de informações, confiança, comprometimento, cooperação, satisfação, lealdade e poder.

Para a dimensão troca de informações, utilizaram-se dois aspectos (Quadro 2), o processo de troca e a qualidade das informações. Em relação aos processos, a troca de informação entre as díades demonstrou ser rápida e diária, fundamentalmente por e-mail, a fim de registrar as informações. As assessorias concordam com a rapidez, mas nem sempre com a precisão, visto que, segundo o Analista de Exportação da Assessoria C, eles dão sequência ao processo de acordo com o que recebem do cliente. Outro relato é apresentado: 
A troca de informações ocorre a partir do momento em que se recebe o e-mail. É feita uma verificação de toda a informação que foi passada. Além disso, no nosso software temos um histórico por cliente. (Analista de Exportação - Assessoria E - Díade A).

De acordo com Palmatier et al. (2006), a troca de informações pode ser expressa pela quantidade, frequência e qualidade. Nas díades estudadas, a quantidade depende diretamente do número de processos realizados, mas, independente desse fator, a frequência é diária. A qualidade, por sua vez, é dependente, muitas vezes, dos dados enviados pelas empresas moveleiras, a qual, por consequência, pode gerar divergências e atrasos caso não seja correta.

Isso reflete o que Dyer $(1996,1997)$ aponta, pois a troca de informações é determinante para o desempenho dos participantes e um dos pré-requisitos mais importantes para um RI bem-sucedido. Gulati e Sytch (2007) reforçam a importância da qualidade da troca e dos tipos de informações, em termos de seus detalhes, precisão e pontualidade, visto que, com isso, pode elevar a capacidade cognitiva e habilidade de processamento das informações.

$\mathrm{Na}$ confiança, tomaram-se como base aspectos como a clareza e transparência nas informações, atitudes como assumir os erros e a liberdade de conversar com os funcionários envolvidos nos processos. Os dados analisados referem-se às informações, às ações e às pessoas (Quadro 2). No quesito confiança em relação às informações, todas as organizações participantes acreditam ser importante a conferência dos dados recebidos, mesmo confiando-se no trabalho do parceiro, pois confiança, conforme descrevem Larentis e Slongo (2008), diz respeito à confidencialidade e veracidade das informações.

Neste ponto, referente às ações, aponta-se como fundamental que os documentos elaborados nos processos de exportação sejam $100 \%$ corretos, pois por meio deles são definidas as condições das operações de compra e venda ao mercado externo, com informações dos compradores e vendedores, e isso reflete diretamente na ponta da cadeia, ou seja, no importador e na qualidade da operação. Evidencia-se também a importância do sigilo e segurança dos dados. Segue relato referente ao sigilo e confidencialidade das informações segundo o Gerente de Exportação da Empresa B:

Meu concorrente mais próximo ou mais longe, eles conseguem informações de mercado, como compradores, volumes de exportação, de importação, isso é público. Então a maior confiança é a questão de confidencialidade. (Gerente de Exportação-Empresa B-Díade A).

Ponto de destaque é a questão do grau de confiança estabelecido entre as pessoas dos setores operacionais das díades estudadas. Mesmo quando se trata de um processo distinto, ou informação diferenciada, a pessoa de contato do dia a dia é a primeira a ser informada. Isso indica que é clara a aceitação da posição hierárquica dos funcionários, mas emerge o respeito pelas pessoas. A gerência fica em cópia (nos e-mails), mas raramente apela-se para a instância superior, conforme relato da Gerente Comercial da Assessoria G:

Sempre se contata o operacional. No momento em que se precisa de um aval de algum diretor, se fala com o operacional. Nunca se passa por cima dela, ou do setor de contato direto, que é a exportação. (Gerente Comercial - Assessoria G - Díade B).

Tal situação apresentada nas três díades, por meio das entrevistas e observações realizadas, reflete o que Morgan e Hunt (1994) e Grönroos (2003) descrevem, pois, quando a confiança está presente, as partes enxergarão os conflitos como sendo construtivos, e a confiança torna-se um dos elementos-chave do relacionamento de longo prazo e das trocas relacionais, reduzindo, da mesma forma, a ansiedade e aumentando a confiabilidade no prestador de serviços.

Para a dimensão comprometimento, conforme o Quadro 2, com as ações e com os 
resultados, as díades evidenciaram a segurança no serviço, busca pelas informações e principalmente cumprimento de prazos (envio de reservas de navios, de draft do conhecimento de embarque, de documentos ao exterior, entre outros).

A Díade A percebe o comprometimento como um elemento diferencial na prestação de serviços, principalmente a questão do atendimento. A Empresa B cita a questão da segurança do serviço, a eficácia nos processos e o feedback rápido. A Assessoria E comenta a questão do investimento em sistemas de informação, por meio de computadores e segurança nos dados, e como isso reflete diretamente na qualidade do atendimento, no serviço e na minimização de erros.

Eu acredito que o comprometimento se reflete dando o feedback na hora e cumprindo os prazos que são estipulados. Várias vezes nós fizemos solicitações com agentes em nome da própria Empresa B, pois temos uma grande preocupação que nada ocorra com problema. (Analista de Exportação - Assessoria E - Díade A).

Reforçando o que já foi mencionado pela Díade A, as Díades B e C também apontam como comprometimento o cumprimento de prazos, feedback imediato, disponibilidade para qualquer esclarecimento e busca pelas informações quando necessário. Compreende-se, por meio das entrevistas e observações, que nas díades o que é descrito como comprometimento por Morgan e Hunt (1994) ocorre em tais RIOs, ou seja, verifica-se o esforço em sustentar a relação, cumprir prazos e dar retornos rápidos, bem como buscar informações quando os processos são distintos dos usuais, ou mesmo melhorar os recursos oferecidos no dia a dia.

Para a dimensão cooperação, os aspectos abordados são a cooperação entre os membros e as atividades realizadas em conjunto. A cooperação entre as díades é peculiar em relação às atividades realizadas em conjunto, visto que cada uma desenvolve estratégias distintas de prestação de serviços. Nas díades pesquisadas, é possível verificar a existência da cooperação entre as empresas, algumas por meio de uma proximidade maior, como as Díades A e B, ou um pouco mais distantes, como no caso da Díade $\mathrm{C}$.

Como diferencial de cooperação, pode-se citar o setor de treinamentos da Assessoria E, participante da Díade A. Por outro lado, verifica-se que, na Díade B, a cooperação é maior e ocorre em diversas situações, não somente no dia a dia das atividades do comércio exterior, mas também por meio de participação em eventos da própria indústria moveleira e outros encontros proporcionados pela assessoria, conforme relato:

Nós cooperamos sim, quando há a necessidade de solucionar alguma dúvida do cliente, a gente conversa junto, procura se adaptar. Acho que a cooperação existe e é muito grande, é ágil e efetiva, e isso é importantíssimo. (Gerente de Exportação - Empresa M - Díade B).

Para Gulati e Sytch (2007), a cooperação é reforçada por meio da ação conjunta. Morgan e Hunt (1994) afirmam que ela é influenciada diretamente pelo comprometimento e pela confiança. Observa-se que, entre as três díades pesquisadas, a Díade B é a que possui uma maior cooperação, apresentando uma sintonia entre os membros, seguida pela Díade A. Nesta dimensão, segundo o Gerente de Exportação da Empresa B, a interação poderia ser melhorada, principalmente com visitas de ambos os lados, para estreitar o relacionamento. Na Díade C, é evidente que a cooperação é somente para o desenvolvimento dos processos, fato que prejudica o relacionamento e, diversas vezes, dificulta o entendimento das partes.

Quanto à satisfação, analisaram-se as semelhanças por meio da satisfação com o serviço prestado e recebido e pelo reconhecimento desse serviço; e algumas peculiaridades foram relacionadas entre as díades, como questões de organização e de inovações nas trocas relacio- 
nais. $O$ aspecto satisfação com o serviço prestado é abordado pelos membros das díades quando os processos ocorrem de maneira correta, na atenção aos detalhes, transparência e flexibilidade para negociar. Entretanto, nas Díade A e C, a falta de inovação tem gerado alguma insatisfação. Segundo Grönroos (1996), os clientes não procuram somente mercadorias ou serviços, mas demandam inovações, além de esperar que isso ocorra em um ambiente cordial e no prazo estipulado entre as partes. A seguir, evidências:

A Assessoria E poderia estar tendo um leque maior de trabalho conosco. Não acontece, pois acredito que não haja interesse deles, pois temos uma relação tão estreita e tão afastada ao mesmo tempo. (Gerente de Exportação - Empresa B - Díade A).

A minha satisfação é com o serviço, de repente nem tenha algo novo para me oferecer, mas esse não saber não me agrada. (Gerente de Exportação - Empresa T - Díade C).

Forti, Marson e Campello (2012) observam que, em serviços, a avaliação da qualidade ocorre ao longo do processo de prestação e que cada contato com o cliente é considerado um momento de verdade, uma oportunidade de satisfazer ou não o cliente. Os autores destacam que os atores do setor de serviços necessitam encontrar alternativas criativas e concretas, a fim de possibilitar melhorias constantes da qualidade, da produtividade e da inovação. Tais pontos são chave para a melhoria dos RIOs segundo descrito pelos gerentes das indústrias moveleiras das Díades A e C. Relativo a isso, destacam-se os agradecimentos e elogios recebidos, os quais geram satisfação e valorização entre os funcionários das assessorias:

E-mail de clientes agradecendo o atendimento, ou que a máquina chegou a tempo, ou que conseguiram fazer a exportação, ou que o processo que não estava conseguindo fazer deu certo... isso gera satisfação. (Gerente Comercial - Assessoria E - Díade A). Receber elogios, agradecimentos, valoriza o nosso trabalho. (Analista de Exportação Assessoria C - Díade C).

Conforme Fornell (2007), as pessoas podem tomar decisões baseadas não na expectativa de valor, mas sim na expectativa de utilidade, ou na satisfação que esperam obter ou punição que esperam evitar. As Empresas B e T possuem uma expectativa de, através da prestação de serviço recebida, obter diferencial competitivo, mas atualmente só recebem a utilidade e comodidade, muitas vezes evitando uma possível baixa de faturamento pela troca de fornecedor, que comprometeria o rendimento no período de transição.

Mesmo com tal situação, ambas as díades demonstram lealdade com os parceiros, principalmente por prezarem pela ética e sigilo das informações e pela permanência da parceria. Tal situação demonstra que a confiança e o comprometimento podem levar a um maior nível de lealdade (Palmatier et al., 2006). Além disso, o desenvolvimento da lealdade dos clientes, no caso as indústrias moveleiras, tem como requisito básico a satisfação, pois, quando satisfeitos, tendem a manter o serviço com os seus fornecedores, (GRÖNROOS, 1996), ou seja, a satisfação é vista muito mais como uma "semente" para florecer a lealdade (OLIVER, 1999).

De acordo com o Quadro 2, os dois principais aspectos analisados foram as intenções e atitudes dos partícipes das díades. No caso da Díade A, os funcionários da Empresa B destacaram que são leais à Assessoria $\mathrm{E}$, por não procurarem outras assessorias e pela própria tradição e confiança. No entanto, apontaram como exceção o laço fraco que é a proximidade da relação:

Não estamos procurando outras assessorias. Não é por envio errado, ou envio duplo que vamos estragar a parceria. Agora precisaria ter um laço maior. Uma aproximação, principalmente da parte deles. (Gerente de Exportação - Empresa B - Díade A). 
A lealdade é vista pela Díade $B$, de acordo com a Empresa $M$, pela confiança presente, clareza nas informações, até mesmo pela agregação de outros serviços, como transporte de contêineres e fretes internacionais. A fala demonstra o que essa dimensão representa:

O que contribui para a lealdade em nosso relacionamento acredito que seja a confiança. Já aumentamos a parceria, não somente despacho, mas transporte rodoviário de contêineres. A assessoria G já agregou o serviço, e isso graças ao trabalho deles. (Gerente de Exportação - Empresa M - Díade B).

Em relação à Díade $\mathrm{C}$, segundo os funcionários da Empresa $\mathrm{T}$, ela possui como filosofia não trocar de parceiros de maneira frequente, e sim construir uma relação de longo prazo. Diante disso, a lealdade da empresa com a assessoria é ressaltada pelos retornos e cumprimento de todas as atividades, clareza e franqueza em todos os momentos. Para a Assessoria C, a lealdade é expressa pela ética em todos os processos e sigilo das informações.

Grönroos (2003) afirma que um prestador de serviços que trabalha com qualidade faz com que os clientes acabem por compreender que ele possui conhecimento e habilidades necessárias para solucionar problemas. Os clientes sentem que o parceiro se interessa em fazer parte das suas dificuldades, solucionando os problemas e auxiliando nos processos. As três citações anteriores exemplificam o RIO da Díade B e evidenciam que, nas Díades A e C, a parte de participar no dia a dia precisa ser melhorada, apesar de o grau de confiança ser alto.

Nas relações de poder, considerando a influência do poder no relacionamento e o uso do poder formal, as díades apontaram os clientes (empresas focais) como possuidores de maior poder no relacionamento. As díades atuam juntas há anos, com confiança, comprometimento e lealdade, mantendo a parceria e não buscando novos fornecedores. Mesmo assim, é importante atentar para tais questões, a fim de não prejudicar as relações com abusos. Como destacam Benton e Maloni (2005), os detentores do poder, ao perceberem que podem obter benefícios no seu desempenho, muitas vezes precisam reanalisar as suas posições dentro da estratégia da cadeia de suprimentos.

Da mesma maneira que na Díade $A$, os envolvidos na Díade $B$ concordam que, na posição de cliente, tem-se uma assimetria de poder, sobretudo quando há fornecedores alternativos mais baratos, incluindo concorrência desleal. No entanto, há preocupação do cliente quanto à qualidade do relacionamento. Como evidência, segue relato:

Com certeza quando se é cliente, tu sempre tens o poder. Em nosso relacionamento nós temos como negociar e argumentar, para poder ter alguns benefícios. Claro que buscamos uma relação de ganha-ganha, uma relação sadia, porque isso é o mais importante. (Gerente de Exportação - Empresa M - Díade B).

Por outro lado, na Díade C, a Empresa T não se considera como detentora do poder, porém a Assessoria $\mathrm{C}$, como as demais, acredita que está no elo mais fraco, pois existem muitas outras assessorias. Observa-se, com as observações e os relatos citados, que raramente se consegue a simetria de poder em um RIO. Gummesson (2005) destaca que, muitas vezes, diante de uma relação importante, a empresa focal possui vantagens, principalmente por estar na posição de cliente. A assimetria, todavia, não significa que não possa haver um relacionamento de qualidade.

He, Ghobadian e Gallear (2013) destacam que a disponibilidade de alternativas determina a dependência entre os membros da cadeia, enquanto a política para a implantação do poder determina o poder de realizar. Juntos, esses dois elementos indicam o nível de interdependência entre as partes. Nesse ínterim, quanto maior a interdependência, maior a importância da aplicação justa de poder nas transações (DWYER; SCHURR; OH, 1987). 
A fim de facilitar o entendimento dos resultados, o Quadro 2 apresenta uma síntese da análise dos dados.

Quadro 2-Resumo dos resultados

\begin{tabular}{|c|c|c|c|c|}
\hline Comparações & Aspectos & Díade A & Díade B & Díade C \\
\hline \multicolumn{5}{|c|}{ Troca de informações } \\
\hline \multirow{2}{*}{ Semelhanças } & $\begin{array}{l}\text { Processo de troca } \\
\text { de informações }\end{array}$ & \multicolumn{3}{|c|}{$\begin{array}{l}\text { Rápida e precisa (indústrias moveleiras)/Rápida, mas nem sempre } \\
\text { precisa (assessorias)/Registro: e-mail/Frequência: diária. }\end{array}$} \\
\hline & $\begin{array}{l}\text { Qualidade das in- } \\
\text { formações }\end{array}$ & \multicolumn{3}{|c|}{$\begin{array}{l}\text { Depende diretamente dos dados recebidos (empresa focal } \times \text { mem- } \\
\text { bro de apoio e vice-versa). }\end{array}$} \\
\hline \multicolumn{5}{|c|}{ Confiança } \\
\hline \multirow{3}{*}{ Semelhanças } & $\begin{array}{l}\text { Em relação às in- } \\
\text { formações }\end{array}$ & \multicolumn{3}{|c|}{$\begin{array}{l}\text { Clareza das informações/Transparência nas informações (principal- } \\
\text { mente na parte financeira da prestação de serviços das assesso- } \\
\text { rias)/Cumplicidade e amizade. }\end{array}$} \\
\hline & $\begin{array}{l}\text { Em relação às } \\
\text { ações }\end{array}$ & \multicolumn{3}{|c|}{$\begin{array}{l}\text { Assumir os erros/Tempo do relacionamento/Liberdade para conver- } \\
\text { sar e realizar os processos. }\end{array}$} \\
\hline & $\begin{array}{l}\text { Em relação às pes- } \\
\text { soas }\end{array}$ & \multicolumn{3}{|c|}{ Comprometimento e respeito à posição hierárquica. } \\
\hline $\begin{array}{l}\text { Peculiarida- } \\
\text { des }\end{array}$ & Percepção & & & $\begin{array}{l}\text { Confiança como } \\
\text { um sentimento, } \\
\text { um feeling. }\end{array}$ \\
\hline \multicolumn{5}{|c|}{ Comprometimento } \\
\hline \multirow{2}{*}{ Semelhanças } & Com as ações & \multicolumn{3}{|c|}{$\begin{array}{l}\text { Segurança do serviço/Eficácia dos processos/Feedback rápido/Dis- } \\
\text { ponibilidade para esclarecimentos/Busca pelas informações. }\end{array}$} \\
\hline & Com os resultados & \multicolumn{3}{|c|}{$\begin{array}{l}\text { Investimento em sistemas de informação/Atuação em nome da } \\
\text { própria empresa (as assessorias)/Cumprimento de prazos. }\end{array}$} \\
\hline \multicolumn{5}{|c|}{ Cooperação } \\
\hline Semelhanças & Entre os membros & \multicolumn{3}{|c|}{$\begin{array}{l}\text { De maneira geral, as organizações em suas díades cooperam entre } \\
\text { si. }\end{array}$} \\
\hline $\begin{array}{l}\text { Peculiarida- } \\
\text { des }\end{array}$ & $\begin{array}{l}\text { Atividades realiza- } \\
\text { das em conjunto }\end{array}$ & $\begin{array}{l}\text { Treinamentos/ } \\
\text { Informativos por } \\
\text { e-mail (assessoria)/ } \\
\text { Auxílio para a reso- } \\
\text { lução de dúvidas do } \\
\text { cliente no exterior. }\end{array}$ & $\begin{array}{l}\text { Visitas a portos e fei- } \\
\text { ras/Participação em } \\
\text { eventos/Preocupação } \\
\text { e auxílio para a reso- } \\
\text { lução de dúvidas do } \\
\text { cliente no exterior/En- } \\
\text { vio de informativos. }\end{array}$ & $\begin{array}{l}\text { Somente proces- } \\
\text { sos/Auxílio para a } \\
\text { resolução de dúvi- } \\
\text { das do cliente no } \\
\text { exterior. }\end{array}$ \\
\hline \multicolumn{5}{|c|}{ Satisfação } \\
\hline \multirow[t]{2}{*}{ Semelhanças } & $\begin{array}{l}\text { Com o serviço } \\
\text { prestado e rece- } \\
\text { bido }\end{array}$ & \multicolumn{3}{|c|}{$\begin{array}{l}\text { Processos ocorrem de maneira correta/Atenção a detalhes, trans- } \\
\text { parência e flexibilidade para poder negociar, auxílio para que o } \\
\text { cliente no exterior receba a documentação correta e em conformi- } \\
\text { dade com a legislação/Proximidade do relacionamento entre seto- } \\
\text { res operacionais. }\end{array}$} \\
\hline & $\begin{array}{l}\text { Reconhecimento } \\
\text { do serviço pres- } \\
\text { tado }\end{array}$ & $\begin{array}{l}\text { Agradecimentos e elo- } \\
\text { gios recebidos. }\end{array}$ & & $\begin{array}{l}\text { Agradecimentos e } \\
\text { elogios recebidos. }\end{array}$ \\
\hline \multirow[b]{2}{*}{$\begin{array}{l}\text { Peculiarida- } \\
\text { des }\end{array}$} & Organização & & $\begin{array}{l}\text { Organização da Em- } \\
\text { presa M. }\end{array}$ & \\
\hline & Inovação & $\begin{array}{l}\text { Oferecer algo novo, } \\
\text { diferenciado/Não so- } \\
\text { mente prestar o servi- } \\
\text { ço básico (Empresa B). }\end{array}$ & & $\begin{array}{l}\text { Oferecer algo } \\
\text { novo, diferencia- } \\
\text { do/Não somente } \\
\text { prestar o serviço } \\
\text { básico (Empresa } \\
\text { T). }\end{array}$ \\
\hline
\end{tabular}




\begin{tabular}{|c|c|c|c|c|}
\hline \multicolumn{5}{|c|}{ Lealdade } \\
\hline Semelhanças & $\begin{array}{c}\text { Intenções e atitu- } \\
\text { des }\end{array}$ & $\begin{array}{c}\text { Continuidade da par- } \\
\text { ceria/Tradição e tem- } \\
\text { po das organizações/ } \\
\text { Transparência nas } \\
\text { cobranças/Sigilo das } \\
\text { informações/Software } \\
\text { utilizado pela asses- } \\
\text { soria. }\end{array}$ & $\begin{array}{c}\text { Confiança entre as or- } \\
\text { ganizações/Agregação } \\
\text { de outros serviços, e } \\
\text { não somente assesso- } \\
\text { ria, como transporte } \\
\text { de contêineres e fre- } \\
\text { tes/Tempo do relacio- } \\
\text { namento. }\end{array}$ & $\begin{array}{c}\text { Retornos e cum- } \\
\text { primento de todas } \\
\text { as atividades/ } \\
\text { Clareza e franque- } \\
\text { za em todos os } \\
\text { momentos/Ética e } \\
\text { sigilo das informa- } \\
\text { ções. } \\
\end{array}$ \\
\hline \multicolumn{5}{|c|}{ Poder } \\
\hline Semelhanças & $\begin{array}{l}\text { Influência do poder } \\
\text { no relacionamento }\end{array}$ & \multicolumn{3}{|c|}{ Acreditam que o cliente possui assimetria de poder. } \\
\hline $\begin{array}{l}\text { Peculiarida- } \\
\text { des }\end{array}$ & $\begin{array}{l}\text { Uso do poder for- } \\
\text { mal }\end{array}$ & $\begin{array}{l}\text { Assessoria E traz o ele- } \\
\text { mento conhecimento } \\
\text { como diferencial de } \\
\text { poder, ou seja, o poder } \\
\text { da informação/Ter o } \\
\text { know how de deter- } \\
\text { minados temas pode } \\
\text { auferir poder. }\end{array}$ & $\begin{array}{l}\text { Assessoria G aponta a } \\
\text { concorrência desleal } \\
\text { (principalmente custos } \\
\text { mais baixos) como for- } \\
\text { ma de poder coercitivo } \\
\text { no relacionamento. }\end{array}$ & $\begin{array}{c}\text { Empresa T não } \\
\text { se percebe como } \\
\text { líder no relaciona- } \\
\text { mento. }\end{array}$ \\
\hline \multicolumn{5}{|c|}{$\begin{array}{c}\text { Aspectos associados à construção do relacionamento interorganizacional e sua interferência no de- } \\
\text { sempenho relacional }\end{array}$} \\
\hline \multirow{3}{*}{ Semelhanças } & $\begin{array}{l}\text { Papéis e orienta- } \\
\text { ções }\end{array}$ & \multicolumn{3}{|c|}{$\begin{array}{l}\text { Bem definidos. } \\
\text { Assessorias como formadoras de profissionais de comércio exterior. }\end{array}$} \\
\hline & $\begin{array}{l}\text { Interação com o } \\
\text { cliente no exterior }\end{array}$ & \multicolumn{3}{|c|}{ Existe essa preocupação entre as empresas. } \\
\hline & $\begin{array}{l}\text { Interação entre } \\
\text { setores }\end{array}$ & \multicolumn{3}{|c|}{$\begin{array}{c}\text { Baixa e insatisfatória em ambos os segmentos (setor moveleiro e } \\
\text { assessorias em comércio exterior). }\end{array}$} \\
\hline $\begin{array}{l}\text { Peculiarida- } \\
\text { des }\end{array}$ & $\begin{array}{l}\text { Visitas (contato } \\
\text { pessoal) }\end{array}$ & $\begin{array}{l}\text { Insatisfatório (Empresa } \\
\text { B). }\end{array}$ & Ótimo (Empresa M). & $\begin{array}{l}\text { Insatisfatório (Em- } \\
\text { presa T). }\end{array}$ \\
\hline
\end{tabular}

Fonte: elaborado pelos autores (2014).

\subsection{Barreiras encontradas nos RIs das díades estudadas}

Partindo dos critérios elencados por Brass et al. (2004), as principais barreiras identificadas nos RIOs associam-se a conflitos no relacionamento, possível encerramento da parceria e suas consequências, qualidade da atuação dos profissionais de comércio exterior e influências de caráter político, econômico e legal.

Verificou-se que a Díade A aponta como barreiras no RIO a inexperiência dos funcionários quando iniciam na atividade e, muitas vezes, o fato de não entenderem o lado um do outro, o que foi destacado principalmente pela Assessoria E. Na Díade C, a maior barreira foi o problema ocorrido com um cliente angolano, que ocasionou a troca do fornecedor de serviços para esse mercado, abrindo margem para o risco da troca integral de parceiro. Em relação a isso, resultados das interações entre assessorias de comércio exterior e empresas exportadoras refletem nas percepções dos importadores sobre o serviço recebido (PHONLOR, 2007).

Foi possível observar que ambas as empresas, mesmo com o encerramento da parceria, seguiriam com os seus processos normalmente; as indústrias necessitariam de um tempo de adaptação com a nova assessoria, o que poderia gerar desgastes e consequente baixa de rendimento dos processos de exportação, resultando ainda em diminuição da eficácia e de faturamento por determinado período. As prestadoras de serviços, por sua vez, buscariam novos clientes para suprir essa lacuna de trabalho e faturamento, além de investigar os motivos do rompimento da parceria, a fim de sanar e melhorar os pontos fracos. No entanto, cabe destacar o relativo baixo custo de troca para as empreas contratantes. 
Como principais conflitos mencionados, estão os de cunho financeiro, como cobranças indevidas, valores diferentes do acordado ou concorrentes oferecendo preços menores. Por fim, umas das maiores dificuldades apontadas por todos é a falta de integração dos profissionais de comércio exterior. As indústrias exportadoras contam pouco com os sindicatos e associações da região e possuem pouco contato com instituições de ensino. As trocas de informações ocorrem de maneira informal, principalmente em feiras e eventos, e com as próprias assessorias, fonte principal de esclarecimento de dúvidas. Da mesma forma, as assessorias não recebem esclarecimentos dos sindicatos e quase não trocam informações com os concorrentes. Para sanar as dúvidas, as assessorias conversam com outras de suas unidades, com pessoas experientes (Assessoria C) ou então realizam pesquisas. Percebe-se que não existe uma unidade de esforços para melhorias nas indústrias envolvidas no comércio exterior. Tampouco as assessorias possuem o setor unido e preparado para as mudanças na legislação e procedimentos do comércio exterior.

Tendo em vista, portanto, os processos envolvidos nos RIs, dimensões constituintes e barreiras apresentadas, percebe-se que as consequências das ações conjuntas entre os parceiros não ficam apenas restritas às díades, assim como as díades dependem de um conjunto de recursos e restrições dos seus contextos, o que ganha maior amplitude em termos internacionais.

\section{CONSIDERAÇÕES FINAIS}

Este estudo teve por objetivo analisar os RIOs no contexto da cadeia de suprimentos, especificamente em três díades no setor moveleiro. De forma resumida, percebeu-se que, com o desenvolvimento dos RIOs, a confiança adquirida ao longo do tempo permitiu, pelo menos na Díade B, qualificar a prestação de serviços. Identificou-se, ainda, que o contato pessoal mais frequente e o fato de os funcionários das díades se conhecerem pessoalmente permitiram um melhor RIO, indo além, muitas vezes, do âmbito profissional.

Todavia, nas Díades A e C, o distanciamento das relações causou o afastamento entre os setores envolvidos e insatisfação com a não apresentação de inovações por parte das assessorias. Evidenciou-se, ainda, que a troca de informações é mais intensa e frequente entre os funcionários dos setores operacionais. Nesse aspecto, a distância espacial interfere no RIO, bem como nas operações, o que é uma parte característica das operações objeto de terceirização (STRINGFELLOW; TEAGARDEN; NIE, 2008).

Em relação às dimensões selecionadas, a troca de informações ocorre com qualidade e a confiança se reflete principalmente na clareza das informações, tempo do relacionamento e respeito mútuo. $\mathrm{O}$ comprometimento se relaciona ao cumprimento dos prazos e à preocupação na eficácia dos processos. Todavia, de forma geral, a quantidade de ações conjuntas é baixa, apesar das afirmações de que existe a cooperação entre as empresas.

A lacuna central identificada foi a falta de um apoio maior aos profissionais da área de comércio exterior, seja por canais internos, seja por meio de sindicatos, associações e instituições de ensino. Ademais, não há uma aproximação entre outros membros da cadeia - que trabalham de maneira isolada, o que afeta a troca de informações -, e, de maneira geral, as organizações partícipes das díades pesquisadas. De certa forma, a falta de integração da cadeia produtiva se reflere em diversos pontos da cadeia de suprimentos das organizações, incluindo o serviço de comércio exterior.

Ambas as díades apontam satisfação com os relacionamentos quando estes ocorrem de maneira adequada e correta, mas a inovação apareceu como ponto a melhorar nas Díades A e C. A lealdade é demonstrada por meio das intenções e atitudes, em especial pelo tempo 
da parceria, que proporciona a continuidade da relação. Por fim, nas relações de poder, ambas apontam para a existência de assimetrias, apesar de associadas a preocupações na qualidade do relacionamento por parte das empresas focais.

Diante do exposto, evidencia-se que, mesmo gerando benefícios e contribuindo para a formação de vantagens competitivas, RIOs dependem de tempo, recursos, trabalho, interações entre os envolvidos e resultados, econômicos e não econômicos (LARENTIS; SLONGO, 2008). Resulta que, tendo compreensão das dimensões dos relacionamentos, os prestadores de serviços podem antecipar, muitas vezes, as necessidades de seus clientes.

Este estudo contribuiu para a prática organizacional, corroborando o que Chopra e Meindl (2011) descrevem, a necessidade de as organizações envolvidas em RIOs convergirem em busca dos benefícios mútuos, em uma relação de ganha-ganha. Dessa forma, mesmo com assimetrias de poder, desde que considerando a relevância de ambas as partes, a troca relacional é mais forte e torna-se colaborativa e de longo prazo.

Aponta-se como um fator limitante o pequeno uso de observações e análises documentais efetuadas no estudo e o fato de o modelo utilizado para a avaliação do desempenho relacional ter sido desenvolvido com o objetivo de avaliar o desempenho internacional, a partir do desempenho exportador. Como sugestões para estudos futuros, recomenda-se aprofundar a pesquisa, estendendo-a aos importadores, a fim de verificar a percepção deles no serviço prestado pelas assessorias e verificar se interfere e/ou contribui no seu desempenho, além de estudos que considerem outros tipos de desempenho empresarial, não somente a dimensão relacional. Também sugere-se investigar o compartilhamento de recursos e de capacidades nos eventuais RIOs construídos entre empresas atuantes em uma mesma cadeia produtiva.

Outro aspecto que merece maior investigação é o papel desempenhado pelos sindicatos, associações e instituições de ensino nas atividades desenvolvidas no setor moveleiro da região e nas próprias assessorias em comércio exterior, ou seja, considerando-se a perspectiva de redes. Por fim, outras dimensões podem ser agregadas ao estudo, como custos de trocas, táticas vinculantes e tipologias do poder.

\section{REFERÊNCIAS}

AGARIYA, A. K.; SINGH, D. What really defines Relationship Marketing? A review of definitions and general and sector-specific defining constructs. Journal of Relationship Marketing, v. 10, $n$. 4, p. 203-237, 2011.

ALIGHIERI, J. S.; FILHO ZANQUETTO, H. Relacionamentos interorganizacionais: uma análise dos aspectos intervenientes da cadeia de serviços do setor de comércio exterior de Vitória (ES). Gestão. Org., v. 7, n. 1, p. 47-68, Jan./Abr. 2009.

ANDERSON, E.; WEITZ, B. Determinants of continuity in conventional industrial channel dyads. Marketing Science, v. 8, n. 4, p. 310-323, 1989.

ANDERSON, J. C.; NARUS, J. A. A model of distribution firm and manufacturer firm working partnerships. Journal of Marketing, n. 54, p. 42-58, Jan. 1990.

BAKER, W. E. Market networks and corporate behavior. American Journal of Sociology, v. 96, $n$. 3, p. 589-625, Nov. 1990.

BARDIN, L. Análise de conteúdo. Lisboa: Edições 70, 2000. 
BENTON, W. C.; MALONI, M. The influence of power driven buyer/seller relationships on supply chain satisfaction. Journal of Operations Management, v. 23, p. 1-22, 2005.

BORTOLLOSSI, L.; SAMPAIO, M. A produção acadêmica publicada na revista Gestão \& Produção de 1999 a 2010: tendências e direções para pesquisas futuras. Gestão \& Produção, v. 19, n. 1, p. 189-201, 2012.

BRASS, D. J. et al. Taking stock of networks and organizations: a multilevel perspective. Academy of Management Journal, v. 47, n. 6, p. 795-817, 2004.

CHEN, I. J.; PAULRAJ, A. Understanding supply chain management: critical research and a theoretical framework. International Journal of Production Research, v. 42, n. 1, p. 131-163, 2004.

CHOPRA, S.; MEINDL, P. Gestão da cadeia de suprimentos: estratégia, planejamento e operações. 4. ed. São Paulo: Pearson Prentice Hall, 2011.

CLARO, D. P. Managing business network and buyer-supplier relationship. Veenendal: Universal Press, 2004.

; CLARO, P. B. O. Gerenciando relacionamentos colaborativos com fornecedores. RAE, V. 44, n. 4, p. 68-79, out./dez. 2004.

CROOM, S.; ROMANO, P.; GIANNAKIS, M. Supply Chain Management: an analytical framework for critical literature review. European Journal of Purchasing \& Supply Management, v. 6, p. 67-83, 2000.

CUNHA, V.; ZWICKER, R. Antecedentes do relacionamento e da performance em empresas da cadeia de suprimentos: estruturação e aplicação de modelos de equações estruturais. RAE, v. 49, n. 2, p. 147-161, abr./jun. 2009.

DWYER, F. R.; SCHURR, P. H.; OH, S. Developing buyer-seller relationships. Journal of Marketing, V. 51, p. 11-27, April 1987.

DYER, J. H. Does governance matter? Keiretsu alliances and asset specificity as sources of Japanese competitive advantage. Organization Science, v. 7, p. 649-666, 1996.

. Effective interfirm collaboration: how firms minimize transaction costs and maximize transaction value. Strategic Management Journal, v. 18, n. 7, p. 535-556, 1997.

; SINGH, H. The relational view: cooperative strategy and sources of inter-organizational competitive advantage. Academy of Management Review, v. 24, n. 4, p. 660-679, 1998.

ELLIS, T. B. The development, psychometric evaluation, and validation of a customer loyalty scale. 2000. Doctoral Dissertation (Doctor of Philosophy degree in Psychology)-Department of Psychology, Southern Illinois University, Cardondale, Illinois, 2000.

ESPER, T. L.; DEFEE, C. C.; MENTZER, J. T. A framework of supply chain orientation. The International Journal of Logistics Management, v. 21, n. 2, p. 161-179, 2010.

FLICK, U. Introdução à pesquisa qualitativa. 3. ed. Porto Alegre: Artmed, 2009.

FLYVBJERG, B. Five misunderstandings about case-study research. Qualitative Inquiry, v. 12, n. 2, p. 219-245, April 2006. 
FORNELL, C. The satisfied customer: winners and losers in the battle for buyer preference, New York: Palgrave MacMillan, 2007.

FORTI, H.; MARSON, J. S.; CAMPELLO, M. O atendimento como diferencial competitivo no setor de serviços para encantar e reter os clientes. In: Simpósio de Engenharia da Produção, 19., 2012, São Paulo. Anais... São Paulo, 2012.

GASKI, J. F. The theory of power and conflict in channels of distribution. Journal of Marketing, $v$. 48, p. 9-29, Summer 1984.

GODOI, C.; MATTOS, P. Entrevista qualitativa: instrumento de pesquisa e evento dialógico. In: GODOY, C.; BANDEIRA-DE-MELLO, R.; SILVA, A. B. (Org.). Pesquisa qualitativa em estudos organizacionais: paradigmas, estratégias e métodos. São Paulo: Saraiva, 2006. p.301-323.

GODOY, A. S. Estudo de caso qualitativo. In: GODOY, C.; BANDEIRA-DE-MELLO, R.; SILVA, A. B. (Org.). Pesquisa qualitativa em estudos organizacionais: paradigmas, estratégias e métodos. São Paulo: Saraiva, 2007. p. 115-146.

GOMES, J. R. S. et al. Satisfação dos serviços: uma análise da percepção dos clientes do Banco do Brasil. Rev. Adm. UFSM, Santa Maria, v. 5, n. 1, p. 126-144, jan./abr. 2012.

GRANDORI, A.; SODA, G. Inter-firm networks: antecedents, mechanisms and forms. Organization Studies, v. 16, n. 2, p. 183-214, 1995.

GRÖNROOS, C. Marketing: gerenciamento e serviços. 2. ed. Rio de Janeiro: Elsevier, 2003. Relationship marketing logic. Asia - Australia Marketing Journal, v. 4, n. 1, p. 7-18, 1996.

GULATI, R.; SYTCH, M. Dependence asymmetry and joint dependence in interorganizational relationships: effects of embeddedness on a manufacturer's performance in procurement relationships. Administrative Science Quarterly, v. 52, p. 32-69, 2007.

GUMMESSON, E. Marketing de relacionamento total: gerenciamento de marketing, estratégias de relacionamento e abordagem CRM para economias de rede. 2. ed. Porto Alegre: Bookman, 2005.

HÅKANSSON, H.; SNEHOTA, I. Developing relationships in business networks. London: Routledge, 1995.

HE, Q.; GHOBADIAN, A.; GALLEAR, D. Knowledge acquisition in supply chain partnerships: the role of power. International Journal of Production Economics, v. 141, p. 605-618, 2013.

HUNT, S. D.; NEVIN, J. R. Power in a channel of distribution: sources and consequences. Journal of Marketing Research (JMR), v. 11, n. 2, p. 186-193, 1974.

; SPEH, T. W. B2B: gestão de marketing em mercados industriais e organizacionais. São Paulo: Cengage Learning, 2011.

KING, N.; HORROCKS, C. Interviews in qualitative research. London: Sage Publications, 2010.

LADEIRA, W. J.; MARCONATTO, D. A. B.; ESTIVALETE, V. B. Controlar para confiar? uma análise do risco percebido em relacionamentos de uma cadeia de suprimentos. Revista Economia \& Gestão, v. 12, n. 29, p. 76-94, maio/ago. 2012. 
LAMBE, C. J.; SPEAKMAN, R. E.; HUNT, S. D. Interimistic relational exchange: conceptualization and propositional development. Journal of the Academy of Marketing Science, v. 28, n. 2, p. 212-225, Spring 2000.

LAMBERT, D. M.; COOPER, M. C. Issues in supply chain management. Industrial Marketing Management, v. 29, p. 65-83, 2000.

LARENTIS, F.; ANTONELLO, C. S.; SLONGO, L. A. Marketing de relacionamento e transformações culturais organizacionais: um estudo de casos múltiplos em díades. In: Encontro da ANPAD, 34., 2010, Rio de Janeiro. Anais... Rio de Janeiro: ANPAD, 2010.

LARENTIS, F.; SLONGO, L. A. Relacionamento em canais de marketing como fonte de vantagem competitiva sustentável: um estudo com fabricantes de móveis e lojas exclusivas. R. Adm., São Paulo, v. 43, p. 209-223, jul./ago./set. 2008.

LI, L. Assessing the relational benefits of logistics services perceived by manufacturers in supply chain. International Journal of Production Economics, v. 132, p. 58-67, 2011.

MALONI, M. J.; BENTON, W. C. Supply chain partnerships: opportunities for operations research. European Journal of Operational Research, v. 101, p. 419-429, 1997.

MARCONI, M. A.; LAKATOS, E. M. Técnicas de pesquisa: planejamento e execução de pesquisas, amostragem e técnicas de pesquisas, elaboração, análise e interpretação de dados. 5. ed. São Paulo: Atlas, 2002.

MENTZER, J. T. et al. Defining supply chain management. Journal of Business Logistics, v. 22, $\mathrm{n}$. 2, p. 1-25, 2001.

MERRIAN, S. B. Qualitative research. San Francisco: Jossey-Bass, 2009.

MILES, M.; HUBERMAN, A. Qualitative data analysis. 2. ed. Thousand Oaks: Sage, 1994.

MORGAN, R. M.; HUNT, S. D. The commitment-trust theory of relationship marketing. Journal of Marketing, v. 58, p. 20-38, July 1994.

OLIVER, C. Determinants of interorganizational relationships: integration and future directions. Academy of Management Review, v. 15, n. 2, p. 241-265, 1990.

OLIVER, R. L. Whence customer loyalty? Journal of Marketing, v. 63, p. 33-44, 1999.

Satisfaction: a behavioral perspective on the consumer. 2. ed. New York: M. E. Sharpe, 2010.

PALMATIER, R. W. et al. Factors Influencing the Effectiveness of Relationship Marketing: A MetaAnalysis. Journal of Marketing, v. 70, p. 136-153, October 2006.

. et al. Relationship velocity: toward a theory of relationship dynamics. Journal of Marketing, v. 77, p. 13-30, January 2013.

PATTON, M. Q. How to use qualitative methods in evaluation. California: Sage Publications, 1987.

PEREIRA, R. C. F.; BELLINI, C. G. P. A perspectiva da díade em relacionamentos entre empresas e clientes de software. In: ANPAD, 30., 2006, Rio de Janeiro. Anais... Rio de Janeiro: ANPAD, 2006.

PHONLOR, P. R. Critérios competitivos e manutenção de relacionamento entre fornecedores 
de transporte marítimo internacional e exportadores do Rio Grande do Sul. 2007. Dissertação (Mestrado em Administração)-Universidade do Vale do Rio dos Sinos, São Leopoldo, 2007.

PIGATTO, G. Avaliação de relacionamentos no canal de distribuição de produtos de mercearia básica. 2005. Tese (Doutorado em Engenharia de Produção)-Universidade Federal de São Carlos, São Carlos, 2005.

PIRANI, S. L.; CUNHA, C. R. A formação da confiança: um estudo no pool da UNIBRASPE. Rev. Adm. UFSM, Santa Maria, v. 3, n. 3, p. 375-392, set./dez. 2010.

PORTER, M. Competição: estratégias competitivas essenciais. 9. ed. Rio de Janeiro, 1999.

RADONS, D. L.; TORRES, C. C.; CERETTA, P. S. Mensuração da satisfação de clientes com serviços de fast food. Revista Eletrônica Estratégia \& Negócios, Florianópolis, v. 5, n. 3, p. 122-150, set./dez. 2012.

RIBEIRO, C. M.; SILVA, C. L. M.; PRADO, P. H. M. Aspectos intervenientes das relações interorganizacionais entre indústrias fornecedoras e uma rede de varejo do segmento alimentício. In: SIMPOI, 12., 2009, São Paulo. Anais... São Paulo: FGV, 2009.

ROBBINS, S. P. Comportamento organizacional. 11. ed. São Paulo: Pearson, 2005.

SCHREIER, M. Qualitative content analysis in practice. London: Sage Publications, 2012.

SCOTT, G.; GARNER, R. Doing qualitative research: designs, methods, and techniques. Upper Saddle River: Pearson, 2013.

SHEPPARD, B. H.; SHERMAN, D. M. The grammars of trust: a model and general implications. Academy of Management Review, v. 23, n. 3, p. 422-437, July 1998.

SIMCHI-LEVI, D.; KAMINSKY, P; SIMCHI-LEVI, E. Cadeia de suprimentos: projeto e gestão. Porto Alegre: Bookman, 2003.

SIRDESHMUKH, D; SINGH, J.; SABOL, B. Consumer trust, value, and loyalty in relational exchanges. Journal of Marketing, v. 66, p. 15-37, jan. 2002.

STRINGFELLOW, A.; TEAGARDEN, M. B.; NIE, W. Invisible costs in offshore services work. Journal of Operations Management, v. 26, p. 167-179, 2008.

TAYLOR, D. A. Logística na cadeia de suprimentos. São Paulo: Pearson, 2005.

VARGO, S. L.; LUSCH, R. F. Service-dominant logic: what it is, what it is not, what it might be. In: LUSCH, R. F.; VARGO, S. L . (Ed.). The service-dominant logic of marketing: dialog, debate, and directions. Armonk, NY: ME Sharpe, 2006. p. 43-56.

YIN, R. K. Estudo de caso: planejamento e métodos. 4. ed. Porto Alegre: Bookman, 2010. 


\section{APÊNDICE A \\ Roteiro básico de questões para as empresas participantes do estudo}

\begin{tabular}{|c|c|c|}
\hline Objetivos específicos & Questões para as empresas do estudo & Autores de base \\
\hline \multirow[t]{5}{*}{$\begin{array}{l}\text { Identificar e analisar as dimen- } \\
\text { sões dos relacionamentos in- } \\
\text { terorganizacionais, no contex- } \\
\text { to de cadeias de suprimento }\end{array}$} & $\begin{array}{l}\text { Troca de Informações } \\
\text { Como ocorre o processo de troca de informações entre a empresa XXX e a } \\
\text { empresa YYY? Que meios são utilizados? } \\
\text { A comunicação tem estreitado os relacionamentos com a assessoria XXX? } \\
\text { Exemplifique. Como isto ocorre? Por que? } \\
\text { Com que frequência essa troca de informações acontece? } \\
\text { Há troca de informação precisa e rápida entre os agentes? Como acontece? }\end{array}$ & $\begin{array}{l}\text { Morgan; Hunt (1994) } \\
\text { Palmatier et al. (2006) } \\
\text { Gulati; Sytch (2007) }\end{array}$ \\
\hline & $\begin{array}{l}\text { Comprometimento } \\
\text { Para você, o que significa comprometimento entre a empresa XXX e a em- } \\
\text { presa YYY? } \\
\text { Descreva como você acredita que se estabelece o processo de compro- } \\
\text { metimento entre a empresa XXX e a empresa YYY (formação, dificuldades, } \\
\text { formas de avaliação). }\end{array}$ & $\begin{array}{l}\text { Morgan; Hunt (1994) } \\
\text { Grönroos (2003) } \\
\text { Gummesson (2005) } \\
\text { Palmatier et al. (2006) } \\
\text { Larentis; Slongo (2008) }\end{array}$ \\
\hline & $\begin{array}{l}\text { Cooperação } \\
\text { De que forma ocorre o processo de cooperação entre a empresa XXX e a empre- } \\
\text { sa YYY? Exemplifique. } \\
\text { Como a cooperação tem contribuído para o relacionamento interorganizacional? } \\
\text { Como você avalia a cooperação de sua empresa com a assessoria XXX e vice e } \\
\text { versa? } \\
\text { Que atividades são feitas em conjunto com a assessoria XXX e vice e versa? }\end{array}$ & $\begin{array}{l}\text { Dwyer; Schurr; Oh } \\
\text { (1987) } \\
\text { Morgan; Hunt (1994) } \\
\text { Håkansson; Snehota } \\
\text { (1995) } \\
\text { Palmatier et al. (2006) } \\
\text { Larentis; Slongo (2008) }\end{array}$ \\
\hline & $\begin{array}{l}\text { Satisfação } \\
\text { Que experiências compartilhadas entre as empresas proporcionaram sa- } \\
\text { tisfação com o relacionamento? } \\
\text { Existem encontros, com o objetivo de buscar a satisfação do cliente no } \\
\text { exterior? Caso positivo, como ocorrem? }\end{array}$ & Palmatier et al. (2006) \\
\hline & $\begin{array}{l}\text { Lealdade } \\
\text { Quais atitudes desempenhadas pela empresa XXX demonstram sua leal- } \\
\text { dade para com a empresa YYY? } \\
\text { O que gera ou que aspectos contribuem para a lealdade em um relacio- } \\
\text { namento interorganizacional? }\end{array}$ & Palmatier et al. (2006) \\
\hline $\begin{array}{l}\text { Identificar e analisar as dimen- } \\
\text { sões dos relacionamentos in- } \\
\text { terorganizacionais, no contex- } \\
\text { to de cadeias de suprimento }\end{array}$ & $\begin{array}{l}\text { Poder } \\
\text { Existe um líder no relacionamento? Quem ele é e quais suas principais } \\
\text { atribuições. } \\
\text { Como se dá o uso de poder? Em que situações ele fica mais evidente? }\end{array}$ & $\begin{array}{l}\text { Dwyer; Schurr; Oh } \\
\text { (1987) } \\
\text { Croom; Romano; Gian- } \\
\text { nakis (2000) } \\
\text { Gummesson (2005) }\end{array}$ \\
\hline $\begin{array}{l}\text { Verificar as barreiras encontra- } \\
\text { das nos relacionamentos in- } \\
\text { terorganizacionais das díades } \\
\text { estudadas }\end{array}$ & $\begin{array}{l}\text { Quais são as maiores dificuldades nesse relacionamento com a empresa } \\
\text { XXX? Por que? O que tem contribuído para isso? Exemplifique. } \\
\text { O encerramento da parceria traria transtornos à empresa? Qual o grau de } \\
\text { dependência da empresa XXX com a empresa YYY? } \\
\text { Os profissionais da área de Comércio Exterior se reúnem para discutir } \\
\text { melhorias para o setor? E como as questões políticas, econômicas e legais } \\
\text { interferem no relacionamento interorganizacional? }\end{array}$ & $\begin{array}{l}\text { Håkansson; Snehota } \\
(1995) \\
\text { Brass et al. (2004) } \\
\text { Gummesson (2005) } \\
\text { Bowersox; Closs; Coo- } \\
\text { per (2007) }\end{array}$ \\
\hline $\begin{array}{l}\text { Analisar como os aspectos } \\
\text { associados à construção do } \\
\text { relacionamento interorganiza- } \\
\text { cional nas díades interferem } \\
\text { no desempenho relacional das } \\
\text { assessorias }\end{array}$ & $\begin{array}{l}\text { Os papéis e orientações estão bem definidos no relacionamento? } \\
\text { Como o relacionamento com outras organizações (outras assessorias) } \\
\text { tem contribuído no desempenho de sua organização? } \\
\text { Conte fatos, situações que demonstrem como o relacionamento entre a } \\
\text { empresa XXX e a empresa YYY ocorrem. }\end{array}$ & $\begin{array}{l}\text { Cooper; Lambert; Pagh } \\
\text { (1997) } \\
\text { Dyer e Singh (1998) } \\
\text { Lambert; Cooper } \\
\text { (2000) } \\
\text { Bowersox; Closs; Coo- } \\
\text { per (2007) }\end{array}$ \\
\hline
\end{tabular}




\begin{tabular}{|c|c|c|}
\hline $\begin{array}{l}\text { Analisar como os aspectos } \\
\text { associados à construção do } \\
\text { relacionamento interorganiza- } \\
\text { cional nas díades interferem } \\
\text { no desempenho relacional das } \\
\text { empresas focais }\end{array}$ & $\begin{array}{l}\text { Os papéis e orientações estão bem definidos no relacionamento? } \\
\text { Como o relacionamento com outras organizações (outras empresas ex- } \\
\text { portadoras) tem contribuído no desempenho de sua organização? } \\
\text { Conte fatos, situações que demonstrem como o relacionamento entre a } \\
\text { empresa XXX e a empresa YYY ocorrem. }\end{array}$ & $\begin{array}{l}\text { Dyer e Singh (1998) } \\
\text { Gummesson (2005) } \\
\text { Ludwig (2006) } \\
\text { Palmatier et al. (2006) } \\
\text { Pereira; Luce (2007) }\end{array}$ \\
\hline
\end{tabular}

Fonte: elaborado pelos autores com base nas bibliografias consultadas (2012-2013-2014).

\section{Roteiro para observação}

\begin{tabular}{|c|c|}
\hline Itens observados & Autores de base \\
\hline $\begin{array}{l}\text { Troca de informações, como o tipo de palavras empre- } \\
\text { gadas (termos ténicos do comércio exterior), nível de } \\
\text { informalidade, conversas paralelas, comentários sobre } \\
\text { outras pessoas das organizações envolvidas. }\end{array}$ & $\begin{array}{l}\text { Morgan; Hunt (1994) } \\
\text { Palmatier et al. (2006) } \\
\text { Gulati; Sytch (2007) }\end{array}$ \\
\hline $\begin{array}{c}\text { Problemas e sinais de conflitos, como indicações de } \\
\text { desconforto gerado pela conversa, tipos de atitudes, } \\
\text { termos utilizados. }\end{array}$ & $\begin{array}{l}\text { Håkansson; Snehota (1995) } \\
\text { Gummesson (2005) } \\
\text { Bowersox; Closs; Cooper (2007) }\end{array}$ \\
\hline $\begin{array}{c}\text { Confiança, comprometimento e cooperação, por meio } \\
\text { de sinais e indicações. Comparações feitas com outras } \\
\text { pessoas das organizações envolvidas. }\end{array}$ & $\begin{array}{c}\text { Morgan; Hunt (1994) } \\
\text { Grönroos (2003) / Claro (2004) } \\
\text { Palmatier et al. (2006) } \\
\text { Gummesson (2005) } \\
\text { Gulati; Sytch (2007) } \\
\text { Larentis; Slongo (2008) }\end{array}$ \\
\hline $\begin{array}{l}\text { Sinais que indiquem o futuro do relacionamento inte- } \\
\text { rorganizacional. }\end{array}$ & $\begin{array}{l}\text { Gummesson (2005) / Ludwig (2006) } \\
\text { Palmatier el al. (2006) / Pereira; Luce (2007) }\end{array}$ \\
\hline
\end{tabular}

Fonte: elaborado pelos autores com base nas bibliografias consultadas (2012-2013-2014). 